\title{
Do Foreign Direct Investment, Energy Consumption and Urbanization Enhance Economic Growth in Six ASEAN Countries?*
}

\author{
Nguyen Tien LONG ${ }^{1}$
}

Received: September 01, 2020 Revised: October 26, 2020 Accepted: November 05, 2020

\begin{abstract}
The neoclassical economic supporters have suggested that foreign direct investment and raw material (e.g., coal, electricity, gas, and oil) are critical economic growth inputs. Few previous studies have analyzed the relationship between foreign direct investment and energy consumption on economic growth. However, existing studies usually have applied the frequentist inference. The limitation of the frequentist inference is that, if the coefficient of the independent variable is not yet significant, then conclusions might be unreliable. By applying the Bayesian approach, the main aim of this study is to revisit the impact of foreign direct investment, electricity consumption, and urbanization on economic growth in six ASEAN countries from 1980 to 2016. The obtained outcome shows that the impact of electricity consumption is evident and positive on economic growth in both frequentist and Bayesian inferences. However, the influence of foreign direct investment is not identified by frequentist inference, while Bayesian inference provides evidence that foreign direct investment is a moderately positive impact on economic growth. The empirical result from Bayesian inference contributes to the literature on foreign direct investment modeling and could be of significant importance for a more efficient foreign direct investment attracting and achieve sustainability in the long-term.
\end{abstract}

Keywords: Foreign Direct Investment, Energy Consumption, Economic Growth, Urbanization, Bayesian Inference

JEL Classification Code: F43, O47, Q42, Q43

\section{Introduction}

In developing countries, the shortage of physical capital to invest in infrastructure, education, hospital, or development occurs rather severely. So, attracting foreign direct investment (FDI) is a logical solution to this situation (Amri, 2016; Batten \& Vo, 2009; Borensztein et al., 1998; Rodrik et al., 2004). The nature of the relationship between FDI and economic growth is decomposed into three main channels, namely: the direct impact, the indirect impact, and the reverse impact. Indeed, the Cobb-Douglas production

\footnotetext{
*Acknowledgments:

We thank anonymous reviewers and the Editor-in-chief for very useful comments and suggestions.

${ }^{1}$ First Author and Corresponding Author. Vice Dean, Faculty of Economics, Thai Nguyen University (TNU) - University of Economics and Business Administration, Vietnam [Postal Address: Tan Thinh Ward, Thai Nguyen City, Thai Nguyen Province, Vietnam]

Email: nguyentienlong@tueba.edu.vn

(c) Copyright: The Author(s)

This is an Open Access article distributed under the terms of the Creative Commons Attribution Non-Commercial License (https://creativecommons.org/licenses/by-nc/4.0/) which permits unrestricted non-commercial use, distribution, and reproduction in any medium, provided the unrestricted non-commercial use,
original work is properly cited.
}

function, i.e., $\mathrm{Q}=\mathrm{f}(\mathrm{K}, \mathrm{L})$ implies that FDI directly contributes to economic growth (EG) through an increase in $\mathrm{K}$. The indirect impact concerns the spillover of FDI effects on the economic structure in the host country and the influence of FDI on the development of domestic firms. The reverse impact considers the bi-directional causality between FDI and EG. The majority of administrators and economic researchers are persuaded that FDI leads to increased physical capital accumulation, encourages competitiveness, boosts household consumption, and creates several new jobs and less unemployment. It is inevitable for domestic enterprises to develop new technologies and new products (Abdouli \& Hammami, 2017; Batten \& Vo, 2009; Le et al., 2019; Markusen \& Venables, 1999; Ngoc \& Hai, 2019).

Most of the production or transportation needs a kind of energy. Understanding and quantifying the relationship between energy consumption (EC) and EG is one of the hot topics for both economics researchers and administrators. Nevertheless, it could not state that the conclusion of existing studies is consistent (Tiba \& Omri, 2017). For example, Long et al. (2018) used the autoregressive distributed lag (ARDL) approach and Toda and Yamamoto (1995) procedure to analyze the impact of FDI and EC on 
gross national income per capita in Vietnam. The empirical result shows that both EC and FDI have a positive impact on EG. However, the causality test outcome provides a mixed-results. Accordingly, there is a bi-directional causal between FDI and EG, while the existence of a unidirectional causality running from EC to EG, supported the Growth hypothesis. The positive impact of EC and FDI on EG is confirmed by the study of Tang (2009) in the case of Malaysia; or the study of Ha et al. (2019); Nguyen and Ngoc (2020) for Vietnam. Nevertheless, the obtained results from the VECM Granger test reveals that there is a uni-directional causality running from EG to EC, which supported the Conversation hypothesis.

Another study by Chen et al. (2007) provides a mixed outcome in the case of ten newly-industrializing and developing ASIAN countries. Accordingly, there is a unidirectional short-run causality running from economic growth to electricity consumption and a bi-directional longrun causality between electricity consumption and economic growth. Apergis and Payne $(2009,2010)$ point out that EC-EG nexus depends on the national development level. In less-developed countries, most economic activities are based on natural extraction, where energy only is used for several basic demands, such as cooking or heating. Thus, EC is not a good contribution to economic growth. However, it is not valid in developing and developed countries where production, transportation, or household activities depends on machinery. All machinery requires a kind of energy to operate, which leads to high demand for essential energies, such as electricity, gas, oil, coal, solar power. Acknowledge that energy consumption is beneficial for growth in these countries. Even energy production is a key determinants of economic growth.

The linkage between FDI-EC-EG nexus is an interesting topic, which is still an ongoing debate (Omri, 2014; Tiba \& Omri, 2017). This work aims to inspect the impact of FDI and EC on EG in six ASEAN nations, including Indonesia, Malaysia, the Philippines, Singapore, Thailand, Vietnam, during the period 1980-2016. Our study is different from several previous studies on multiple points, as follows: First, to the best of our knowledge, the available studies analyzed in the case of ASEAN countries have drawn little attention. Second, most previous studies have been conducted in a linear framework and used the frequentist inference. In the study, we employed the Bayesian inference approach through the integrated Markov chain Monte-Carlo sampler to provide probabilistic interpretations of model uncertainty and varying effects of FDI, EC, and urbanization (plays as a control variable) on economic growth. The advantage of Bayesian inference compared to frequentist inference is presented in Section 3. To our knowledge, the obtained result could be enrichment in existing economic literature and for the ASEAN nations in particular.
The rest of the study is organized as follows: Section 2 focuses on present the literature and the existing studies. Section 3 describes the model, data, and methodology. The obtained outputs are shown in Section 4, while Section 5 provides a conclusion and policy implication.

\section{Literature Review}

\subsection{The Interaction Between Foreign Direct Investment and Economic Growth}

In the 1970s, several pioneering studies such as Hymer (1976) stated that FDI is beneficial for economic growth because it is a technology transfer source and spillovers. There is a massive impact of FDI on the economic structure of the host country. The majority of administrators and economic researchers is believed that FDI leads to an increase in exports, rises in the level of living standards, less unemployment, improving the balance of payments, and provides some other welfares (Borensztein et al., 1998; Carkovic \& Levine, 2002; Hussain \& Haque, 2016; Ngoc, 2020). Alfaro et al. $(2004,2010)$ inspect the influences of multinational companies on the host country. Using realistic parameter values, the obtained outcome reveals an increase in FDI share leads to higher additional growth in financially developed economies. Likewise, Ibrahiem (2015) used the ARDL bounds testing approach to discovers the linkage between renewable EC, FDI, and EG in Egypt from 1980 to 2011. The result found that cointegration exists among examined variables, and both EC and FDI have a positive influence on EG. Besides, the Feedback hypothesis between EC and EG is found by the Granger causality test. A similar conclusion is confirmed by the study of Amri (2016) for 75 countries in the period 1990-2010.

The technology transfer and innovation of FDI are confirmed by the study of Erdal and Göçer (2015). Accordingly, two authors want to analyze the wealth of FDI on the R\&D and innovation activities of domestic firms in ten developing ASIAN countries. By applying the fully modified least square (FMOLS) method, and the Dumitrescu and Hurlin (2012) non-granger causality test, the obtained outcome provides evidence that FDI inflows significantly affect on R\&D expenditures and innovation activities in host nations. Indeed, a one-point increase in the FDI inflow amount leads to a 0.83 percent increase in R\&D expenses and a 0.42 percent increase in patent applications in these nations during 1996-2013. Consistent with this conclusion, Sivalogathasan and $\mathrm{Wu}$ (2014) investigate the spillover of FDI on absorptive capacity and domestic innovation capability in South Asian countries from 2000 to 2011. The study found that local R\&D expenditure is a very significant determinant of innovation capability, and the coefficient of the FDI variables is positive and significant. This implies 
that a one percent increase in FDI inflow is associated with 40 percent increase in the number of patent applications.

Analysis for five BRICS countries, Hayrdaroglu (2016) examines the interaction between FDI, economic freedom, and EG over 1995-2013. The results indicate that FDI is positively related and statistically significant determinant of economic growth. Besides, the obtained outcome showed that economic freedom is a key determinant of effective FDI attracting policy. The conclusion of Hayrdaroglu (2016) is also confirmed by Maryam and Mittal (2020). Recently, Pradhan et al. (2019) inspect the linkage between economic growth, stock market depth, trade openness, and FDI in 25 ASEAN regional forum countries. The empirical results from the VECM approach support the conclusion that trade openness, FDI, and the various measures of stock market depth Granger-cause economic growth in the long run. Ngoc and Hai (2019), Nguyen (2020) also found that FDI leads to a massive change in the structure of Vietnam's economy. Indeed, FDI encourages the development of the industrial sector and reduces the agricultural and forest contribution to economic growth.

However, some administrators and economics researchers are not advocating for FDI. A popular reason is submitted that FDI causes pollution (Abdouli \& Hammami, 2017; Behera \& Dash, 2017; Kivyiro \& Arminen, 2014; Liu et al., 2018), exhausts natural resources (Markusen \& Venables, 1999; Pazienza, 2015), and destroys the development of domestic enterprises (Le et al., 2019). Prebisch (1968) argues that the target countries of FDI receive very few benefits, due to most benefits are transferred to the home country. Blomstrom et al. (1992) stated that FDI from developed countries is harmful to the economic growth of developing countries in the long-term. Emerging countries have a low financial institution and should be highly susceptible to the global financial market's volatility, which is especially severe for countries with an open capital account. Ang (2009) used an unrestricted error-correction model to examine the roles of foreign direct investment and financial development in economic development in the case of Thailand from 1970 to 2004. The result shows that there is a weak negative impact of FDI on EG. Likewise, Temiz and Gökmen (2014) concludes that no significant relation is determined between the FDI inflow and GDP growth in Turkey both in the short and long run. No interaction between FDI and EG is found by the study of Irandoust (2001), Carkovic and Levine (2002).

\subsection{Energy Consumption and Economic Growth}

In developing countries, administrators and economic researchers have advocated analysis of the linkage between energy consumption and economic growth with the expectation that energy production and energy consumption are key determinants of economic growth. In fact, energy is a necessary input of economic activities, such as transportation, production (Abosedra et al., 2009; Chandran et al., 2010; Golam \& Nazrul, 2011; Ngoc, 2019; Zhang et al., 2017). The EC-EG nexus has been well-studied in the energy economics literature. However, the available studies have failed to provide a consistent answer (Ha \& Ngoc, 2020; Tiba \& Omri, 2017), and it is still the subject of an ongoing policy debate. There are four hypotheses found by existing works about the relationship between EC and EG, including the "Conversation", the "Growth", the "Feedback" and the "Neutrality" hypothesis.

Supporting the Feedback hypothesis, based on the Cobb-Douglas production function, Hamdi et al. (2014) inspect the linkages between electricity consumption, FDI, capital, and economic growth from 1980Q1 to 2010Q4 for the Kingdom of Bahrain. The empirical result from the ARDL bounds testing and VECM causality shows a positive and bi-directional causality between electricity consumption and EG. Likewise, Ibrahiem (2015) analyzes the relationship between renewable electricity consumption, FDI, and economic growth in Egypt during 1980-2011. The existence of cointegration among the examined variable is found by the ARDL bounds testing, and the Granger causal test identifies the bi-directional causality between EG and renewable electricity consumption. The positive influence of EC on EG is confirmed by the study of Tang (2009) for Malaysia, Long et al. (2018); Nguyen and Ngoc (2020) for Vietnam, or Zhang et al. (2017) for China's economy.

About the Growth hypothesis, Golam and Nazrul (2011) discover the connection between per capita electricity consumption and per capita GDP in the case of Bangladesh from 1971 to 2008. The obtained outcome reveals mixed results. Accordingly, there is a uni-directional causality in the short-run, a bi-directional causality between per capita electricity consumption and per capita GDP in the long-run. Another study by Acaravci (2010) explores the short- and long-run causality issues between electricity consumption and EG in Turkey from 1968 to 2005. The VECM Granger causality shows that there is a uni-directional causality running from electricity consumption to economic growth.

The Conversation hypothesis was found by the pioneering study of Kraft and Kraft (1978). They examine the impact of economic growth on electricity consumption in the United States over the period 1947-1974. The Granger causality provides that there is a uni-directional causality running from EG to electricity consumption. Likewise, Balcilar et al. (2019) used the Maki cointegration to inspect the linkage between electricity consumption, real gross domestic product, and Pakistan's carbon dioxide emissions. A uni-directional causality running from EG to electricity consumption was found by the Toda-Yamamoto causality test, which supported the Conversation hypothesis. 
Some studies found the Neutrality hypothesis. Ghosh (2009) does not found the interaction between electricity supply, employment, and real GDP for India. Similarly, Payne (2009) applied the Toda-Yamamoto causality tests, and the obtained result shows that the absence of Granger-causality between renewable or non-renewable energy consumption and real GDP in the case of the United States from 1949 to 2006, which supports the neutrality hypothesis. Of course, the studies mentioned above do not adequately represent all previous studies on FDI-EC-EG nexus. Nevertheless, this review showed that most of the available studies use frequentist inference. Near no studies apply Bayesian inference. It is a methodology gap, which this work wants to address.

\section{Research Model and Methodology}

Based on the Cobb-Douglas production function, the main aim of this study is to investigate the impact of FDI and electricity consumption on economic growth in six ASEAN countries from 1980 to 2016 , so the model is preliminarily set as follows:

$$
\begin{aligned}
\operatorname{LnGDP_{i,t}=} & \beta_{0}+v_{i}+\beta_{1} \cdot \operatorname{LnEC} C_{i, t}+\beta_{2} \cdot \operatorname{LnFDI}_{i, t} \\
& +\beta_{3} \cdot \operatorname{Ln}(E C \cdot F D I)_{i, t}+\beta_{4} \cdot U B_{i, t}+e_{i, t}
\end{aligned}
$$

where, $\mathrm{i}$ is the country $(1, \ldots, \mathrm{N}$ : including Indonesia, Malaysia, the Philippines, Singapore, Thailand, Vietnam, respectively), $\mathrm{t}$ is time $\left(1, \ldots, \mathrm{T}\right.$ : from 1980 to 2016). $v_{i}$ is the random intercept of each country, $\mathrm{e}_{(i, t)}$ is an error. In Eq.1, the FDI variable is foreign direct investment per capita (units: U.S. dollar), the EC variable is electricity consumption per capita (unit: $\mathrm{kWh} /$ year), (EC.FDI) is the interaction variable, and $\mathrm{UB}$ is the rate of urbanization (unit: percentage), which plays as the control variable in the model. Annual data is collected from the International Energy Agency and the World Bank. The dependent variable is GDP per capita (at the fixed price 2010, unit: U.S. dollar). This work used the Bayesian inference, which has several advantages outperforms the Frequentist inference, as follows:

First, Bayesian analysis is based on the Bayes rule, and the posterior distribution results from updating the prior knowledge about model parameters with evidence from the observed data. The Bayesian analysis rests on Bayes' theorem of probability theory:

$$
p(\theta \mid y)=\frac{p(y \mid \theta) \cdot p(\theta)}{p(y)}
$$

where, $\theta$ stands for a set of unknown parameters, (y) represents a marginal distribution of data, $p(\theta)$ denotes the prior distribution of the parameters $\theta$ (pre-existing information such as expert opinion, theory, or other external resources), $p(y \mid \theta)$ is a likelihood distribution, $p(y)$ is the marginal distribution of $\mathrm{y}$, and $p(\theta \mid y)$ denotes the posterior distribution, which is the probability of the parameters $\theta$ conditional on the data (y). (Eq.2) may be expressed as:

$$
p(\theta \mid y) \propto p(y \mid \theta) p(\theta)
$$

where, $\propto$ implies "proportional to". The posterior is proportional to the prior multiplied by the likelihood.

Second, the frequentist inference assumes that all parameters are considered unknown but fixed quantities, while Bayesian inference allows all parameters are random quantities and thus can incorporate prior knowledge. Hence, Bayesian analysis yields an entire probability distribution of a parameter, while frequentist results are point estimates. Also, the Bayesian paradigm allows for probability statements, such as a variable is likely or unlikely to impact another, or the true value of a parameter falls into a certain interval with a pre-specified probability (Bernardo \& Smith, 1994; Thompson, 2012).

Because our data sample size is sufficiently large, noninformative priors are enough for our model specification. For comparison purposes, we also specify informative priors for the model parameters. Accordingly, we conduct five posterior simulations. A sensitivity analysis to prior choice will be performed through a Bayes factor test and a model test. We assume to have models $\mathrm{M}_{j}$ parameterized by vectors $\theta_{j}, j=1,2, \ldots, r$. By applying Bayes's theorem, we calculate the posterior model probabilities:

$$
p\left(M_{j} \mid y\right)=\frac{p\left(y \mid M_{j}\right) p\left(M_{j}\right)}{p(y)}
$$

Since it is challenging to calculate $p(y)$, a popular practice is to compare two models, for example, $\mathrm{M}_{j}$ and $\mathrm{M}_{k}$ via posterior odds ratio:

$$
P O_{j, k}=\frac{p\left(M_{j} \mid y\right)}{p\left(M_{k} \mid y\right)}=\frac{p\left(y \mid M_{j}\right) p\left(M_{j}\right)}{p\left(y \mid M_{k}\right) p\left(M_{k}\right)}
$$

If all models are equally plausible, that is $p\left(M_{j}\right)=1 / r$, the posterior odds ratio is transformed into the Bayes factor, which is simply ratios of marginal likelihoods (Jeffreys, 1962).

$$
B F_{j, k}=\frac{p\left(y \mid M_{j}\right)}{p\left(y \mid M_{k}\right)}
$$

The detailed process of estimation is acted through three steps, as follows:

First, we use the fixed-effect model (FEM) and the random-effect model (REM) to provide a general view of the influence of FDI, EC, and UB variables on economic growth. 
Second, we apply the Bayesian approach via the Metropolis-Hasting and Gibbs samplers as the MCMC methods to estimate each independent variable's impact on economic growth.

\section{Empirical Results}

\subsection{Descriptive Statistics}

In two past decades, the six ASEAN nations, including Indonesia, Malaysia, the Philippines, Singapore, Thailand, and Vietnam, have changed rapidly in most socio-economic fields. Rapid growth leads to a change in the structure of the economy. The industry sector is focused on investing by the Government. Also, urbanization leads to a great demand for energy. Acknowledge that FDI and energy consumption are actively contributing to growth in these countries. The descriptive statistic of all variables is shown in Table 1.

\subsection{Model Comparison}

This subsection compares five posterior regression models, where the respective Gaussian prior distributions specified are $\mathrm{N}(0,1), \mathrm{N}(0,10), \mathrm{N}(0,100), \mathrm{N}(0,1000)$, and $\mathrm{N}(0,10000)$. The results of the model comparison are presented in Tables 2 and Table 3. In general, the less the DIC value, the more the $\log (\mathrm{ML})$ and $\log (\mathrm{BF})$ estimate, the better a model fits the data. P(My) shows the posterior model probability. Consequently, model 2 is the best.

\subsection{Markov Chain Monte Carlo (MCMC) Convergence Test}

In the application of an MCMC method, a convergence check is needed before proceeding to inference. Once chain convergence is established, the model parameters have converged to equilibrium values. This study simulates three MCMC chains and verifies whether the results satisfy the convergence rule to avoid spurious convergence. This is because spurious convergence occurs when the chains have seemingly converged, but they have only explored only a portion of the posterior distribution domain. As demonstrated in Table 4, the maximum Gelman-Rubin statistic Rc of 1.000206 is close to 1.1, indicating MCMC convergence.

Table 1: The descriptive statistic of all variables.

\begin{tabular}{|l|c|c|c|c|}
\hline Variables & Mean & Maximum & Minimum & Std.Error \\
\hline LnGDP & 8.128 & 10.885 & 5.735 & 1.234 \\
\hline LnEC & 6.763 & 9.088 & 3.832 & 1.358 \\
\hline LnFDI & 4.072 & 9.509 & -0.001 & 0.725 \\
\hline LnECFDI & 10.67 & 18.59 & -3.093 & 3.954 \\
\hline UB & 50.26 & 100 & 19.25 & 25.56 \\
\hline
\end{tabular}

Table 2: Bayesian information criteria

\begin{tabular}{|l|c|c|c|c|}
\hline Model & Gaussian distribution & Avg. DIC & log(ML) & log(BF) \\
\hline 1 & $\mathrm{~N}(0,1)$ & 133.1145 & -96.8954 &. \\
\hline 2 & $\mathrm{~N}(0,10)$ & 132.4780 & -94.4735 & 2.4218 \\
\hline 3 & $\mathrm{~N}(0,100)$ & 132.4787 & -99.3797 & -2.4844 \\
\hline 4 & $\mathrm{~N}(0,1000)$ & 132.4795 & -105.0508 & -8.1555 \\
\hline 5 & $\mathrm{~N}(0,10000)$ & 132.4795 & -110.7987 & -13.9034 \\
\hline
\end{tabular}

Table 3: Bayesian model tests

\begin{tabular}{|l|c|c|c|c|}
\hline Model & Gaussian distribution & $\log (\mathbf{M L})$ & $\mathbf{P}(\mathbf{M})$ & $\mathbf{P}(\mathbf{M y})$ \\
\hline 1 & $\mathrm{~N}(0,1)$ & -96.8954 & 0.2000 & 0.0810 \\
\hline 2 & $\mathrm{~N}(0,10)$ & -94.4735 & 0.2000 & 0.9123 \\
\hline 3 & $\mathrm{~N}(0,100)$ & -99.3797 & 0.2000 & 0.0068 \\
\hline 4 & $\mathrm{~N}(0,1000)$ & -105.0508 & 0.2000 & 0.0000 \\
\hline 5 & $\mathrm{~N}(0,10000)$ & -110.7987 & 0.2000 & 0.0000 \\
\hline
\end{tabular}


The model summary reports the rate of acceptance and algorithm efficiency as initial indicators of MCMC convergence. The acceptance rate is the number of proposals accepted in the total proposals, whereas algorithm efficiency is the mixing properties of MCMC sampling. Concerning the chosen model 2 , the acceptance rate of 0.8418 is larger than the minimum level of 0.1 , whereas average efficiency is equivalent to 0.3271 , which is more than the acceptable level of 0.01 . Additionally, it is useful to conduct a graphical inspection. For this, CUSUM plots as an accessible tool are applied. As shown in Figure 1, the CUSUM plots of the three chains' parameters are jagged, not smooth, running across the X-axis. So MCMC chains for the model parameters are well-mixed, which is a sign of sequence convergence.

Table 4: Gelman-Rubin convergence diagnostic

\begin{tabular}{|l|c|}
\hline Max Gelman-Rubin Rc $\mathbf{1 . 0 0 0 2 0 6}<$ Convergence rule (=1.1) & Rc value \\
\hline Dependent variable: LnGDP & 1.000057 \\
\hline LnEC & 1.000072 \\
\hline LnFDI & 0.999971 \\
\hline LnECFDI & 0.999968 \\
\hline UB & 1.000206 \\
\hline Intercept & 0.8418 \\
\hline Average acceptance rate & 0.3271 \\
\hline Average efficiency rate & $\mathbf{0 . 9 9 9 9 9 5}$ \\
\hline var & \\
\hline
\end{tabular}

\section{Cusum plots}

Ingdp:Inec

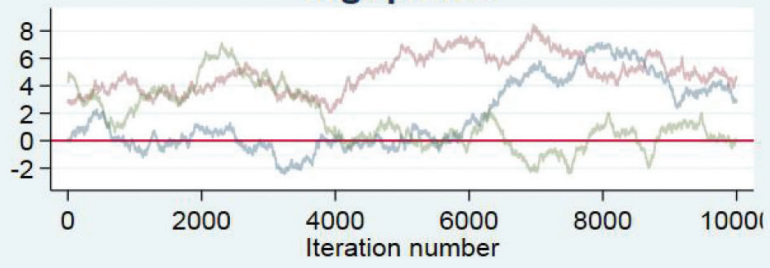

Ingdp:Inecfdi

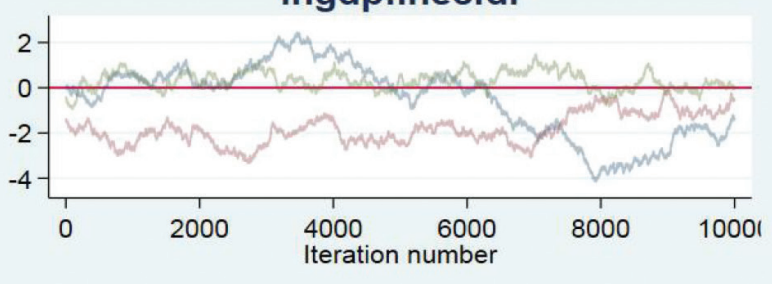

Ingdp:_cons

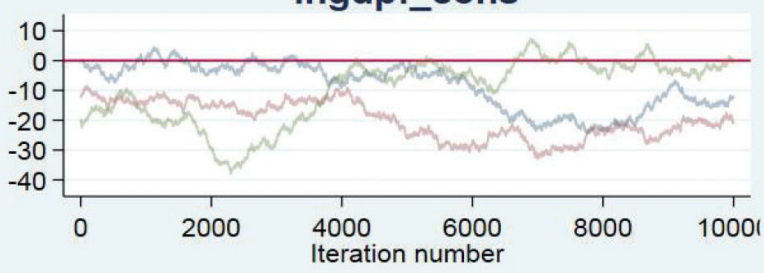

Ingdp:Infdi

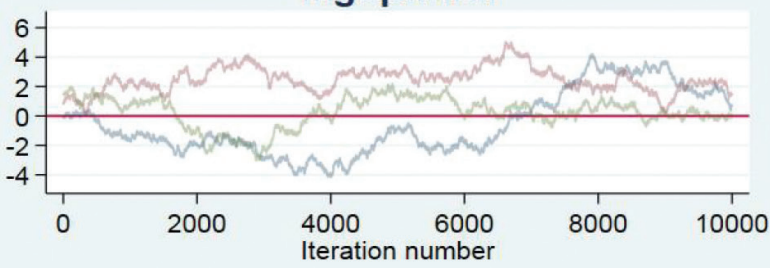

Ingdp:ub
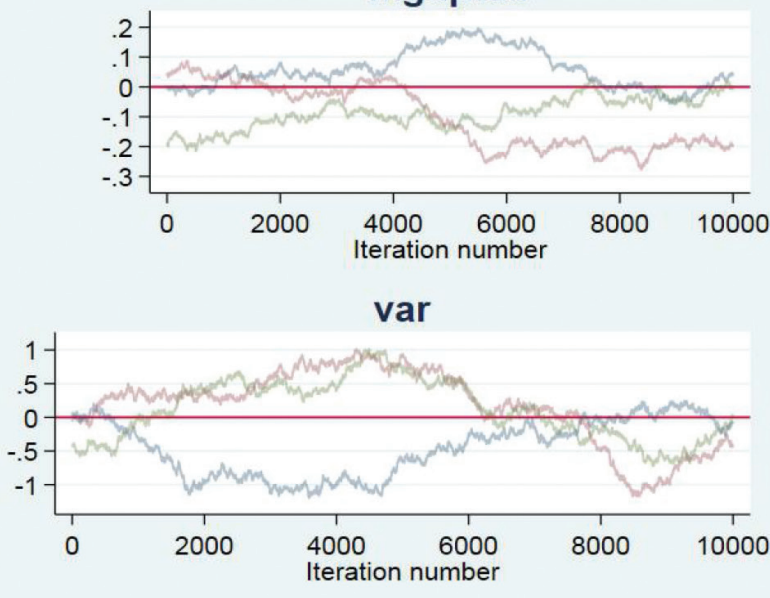

Chains: $1 / 3$

Figure 1: CUSUM plots of model parameters 
Table 5: FEM, REM and Bayesian simulation results

\begin{tabular}{|c|c|c|c|c|c|}
\hline \multirow{2}{*}{ Variables } & \multicolumn{2}{|c|}{ Coefficient } & p_value & Coefficient & p_value \\
\hline & \multicolumn{2}{|c|}{ FEM result } & \multicolumn{3}{|c|}{ REM result } \\
\hline LnEC & \multicolumn{2}{|c|}{0.5353} & 0.000 & 0.2912 & 0.000 \\
\hline LnFDI & \multicolumn{2}{|c|}{0.1326} & 0.000 & 0.0159 & 0.721 \\
\hline LnECFDI & \multicolumn{2}{|c|}{-0.0546} & 0.000 & 0.0514 & 0.098 \\
\hline UB & \multicolumn{2}{|c|}{-0.0049} & 0.023 & 0.0240 & 0.009 \\
\hline Intercept & \multicolumn{2}{|c|}{4.8048} & 0.000 & 4.3419 & 0.000 \\
\hline F-test & \multicolumn{5}{|c|}{ F-statistic $=286.31\left(p \_\right.$value $\left.=0.000\right)$} \\
\hline \multirow[t]{2}{*}{ Hausman test } & & \multicolumn{4}{|c|}{ F-statistic $=249.49\left(p_{\text {_value }}=0.000\right)$} \\
\hline & & \multicolumn{4}{|c|}{ Bayesian result } \\
\hline Variables & Mean & Std. Dev. & MCSE & $\begin{array}{l}\text { Probability } \\
\text { of mean }>0\end{array}$ & $\begin{array}{c}\text { Equal-tailed } \\
\text { [95\% Cred. Interval] }\end{array}$ \\
\hline \multicolumn{6}{|c|}{ Dependent variable: LnGDP } \\
\hline LnEC & 0.2953 & 0.0583 & 0.00034 & 1 & {$[0.1812,0.4101]$} \\
\hline LnFDI & 0.0152 & 0.0445 & 0.00026 & 0.638 & {$[-0.0729,0.1024]$} \\
\hline LnECFDI & 0.0507 & 0.0311 & 0.00018 & 0.949 & {$[-0.0103,0.1117]$} \\
\hline UB & 0.0239 & 0.0018 & 0.00001 & 1 & {$[0.0205,0.0274]$} \\
\hline Intercept & 4.3251 & 0.2044 & 0.00118 & 1 & {$[3.9228,4.7243]$} \\
\hline
\end{tabular}

\subsection{FEM, REM, and Bayesian Estimation}

The estimation of the (Eq.1) by frequentist and Bayesian inference is presented in Table 5. The FEM and REM model's obtained outcome shows a positive impact of EC on EG. Applying the REM model, a one percent increase in EC leads to a 0.29 percent increase in EG. Besides, FDI is beneficial for economic growth, but not yet significant $\left(p \_v a l u e>0.1\right)$. In this situation, we could not provide a conclusion or suggest any policy implications. This is a disadvantage of frequentist inference.

With the Bayesian inference, the result in the lower section of table 5 reveals that both the influence of EC and FDI is positive and significant. However, with a probability of mean between 0.7 and 1, EC exerts a powerfully positive effect on EG, while the 63.8 percent probability denotes that the influence of FDI on EG is a moderately impact. The 95 percent credible intervals also point to similar results. Compared to frequentist statistics, credible Bayesian intervals have direct and intuitive probabilistic interpretation. The mean of the LnECFDI variable is positive, which means energy supply is a key determinant of FDI inflow attracting capacity into six ASEAN countries. With a probability of mean being one, we can state that urbanization contributes to economic growth in examined nations.

\subsection{Discussion}

The empirical result shows that the impact of FDI on economic growth is moderate. Compared with previous studies, this result is the same as the conclusion of Maryam and Mittal (2020) for BRICS countries, Erdal and Göçer (2015), for ten ASIAN developing nations. Indeed, FDI has changed several socio-economic fields in these countries. Reports of the UNCTAD showed that ASEAN countries are an attractive destination for multinational enterprises, in which total FDI inflows exceed 10 billion U.S dollars per year. Regarding the effect of energy consumption on growth, the obtained result of this study is in line with the conclusion by Osman et al. (2016) for GCC countries, Chen et al. (2007) for ten ASEAN nations, or Squalli (2007) for OPEC members. All six countries in our sample are developing or developed countries, so the demand for production, distribution, or household consumption is rapid. Thus, energy production is a priority policy issued by the Government in examined countries.

\section{Conclusion}

The study applies the Bayesian approach via the Metropolis-Hasting and Gibbs samplers as the MCMC methods to investigate the impact of foreign direct 
investment, electricity consumption, and urbanization on economic growth in six ASEAN countries from 1980 to 2016. According to the obtained estimation results, we claim the probability that electricity consumption strongly and positively affects economic growth, while foreign direct investment is moderate.

Based on the empirical results, some policy implications are suggested:

Firstly, energy consumption is beneficial for growth. It is recommended that these nations explore many new energies, such as renewable energy, solar or biological power.

Secondly, FDI has a positive impact on economic growth. It is implied that the Government should consider and allow FDI projects, which used green or high technology. The Government should also encourage FDI projects, which have invested in $\mathrm{R} \& \mathrm{D}$ activities or transfer technological know-how.

\section{References}

Abdouli, M., \& Hammami, S. (2017). Investigating the causality links between environmental quality, foreign direct investment and economic growth in MENA countries. International Business Review, 26(2), 264-278.

Abosedra, S., Dah, A., \& Ghosh, S. (2009). Electricity consumption and economic growth, the case of Lebanon. Applied Energy, $86(4), 429-432$

Acaravci, A. (2010). Structural breaks, electricity consumption and economic growth: Evidence from Turkey. Romanian Journal of Economic Forecasting, 2, 140-154.

Alfaro, L., Chanda, A., Kalemli-Ozcan, S., \& Sayek, S. (2004). FDI and economic growth: the role of local financial markets. Journal of International Economics, 64(1), 89-112.

Alfaro, L., Chanda, A., Kalemli-Ozcan, S., \& Sayek, S. (2010). Does foreign direct investment promote growth? Exploring the role of financial markets on linkages. Journal of Development Economics, 91(2), 242-256.

Amri, F. (2016). The relationship amongst energy consumption, foreign direct investment and output in developed and developing Countries. Renewable and Sustainable Energy Reviews, 64, 694-702.

Ang, J. B. (2009). Foreign direct investment and its impact on the Thai economy: the role of financial development. Journal of Economics and Finance, 33(3), 316-323.

Apergis, N., \& Payne, J. E. (2009). Energy consumption and economic growth in Central America: Evidence from a panel cointegration and error correction model. Energy Economics, 31(2), 211-216.

Apergis, N., \& Payne, J. E. (2010). Energy consumption and growth in South America: Evidence from a panel error correction model. Energy Economics, 32(6), 1421-1426.
Balcilar, M., Bekun, F. V., \& Uzuner, G. (2019). Revisiting the economic growth and electricity consumption nexus in Pakistan. Environ Sci Pollut Res Int, 26(12), 12158-12170.

Batten, J. A., \& Vo, X. V. (2009). An analysis of the relationship between foreign direct investment and economic growth. Applied Economics, 41(13), 1621-1641.

Behera, S. R., \& Dash, D. P. (2017). The effect of urbanization, energy consumption, and foreign direct investment on the carbon dioxide emission in the SSEA (South and Southeast Asian) region. Renewable and Sustainable Energy Reviews, 70, 96-106.

Bernardo, J. M., \& Smith, A. F. M. (1994). Bayesian Theory. Hoboken, NJ: John Wiley \& Sons, Inc.

Blomstrom, M., Lipsey, R. E., \& Zejan, M. (1992). What explains developing country growth? NBER Working Paper Series No., 4132.

Borensztein, E., Gregorio, J. D., \& Lee, J. W. (1998). How does foreign direct investment affect economic growth? Journal of International Economics, 45(1), 115-135.

Carkovic, M. V., \& Levine, R. (2002). Does foreign direct investment accelerate economic growth? Department of Finance Working Paper, 6, 1-23, University of Minnesota.

Chandran, V. G. R., Sharma, S., \& Madhavan, K. (2010). Electricity consumption-growth nexus: The case of Malaysia. Energy Policy, 38(1), 606-612.

Chen, S.-T., Kuo, H.-I., \& Chen, C.-C. (2007). The relationship between GDP and electricity consumption in 10 Asian countries. Energy Policy, 35(4), 2611-2621.

Dumitrescu, E.-I., \& Hurlin, C. (2012). Testing for Granger noncausality in heterogeneous panels. Economic Modelling, 29(4), $1450-1460$.

Erdal, L., \& Göçer, İ. (2015). The Effects of Foreign Direct Investment on R\&D and Innovations: Panel Data Analysis for Developing Asian Countries. Procedia - Social and Behavioral Sciences, 195, 749-758.

Ghosh, S. (2009). Electricity supply, employment and real GDP in India: evidence from cointegration and Granger-causality tests. Energy Policy, 37(8), 2926-2929.

Golam, A. M., \& Nazrul, I. A. K. M. (2011). Electricity consumption and economic growth nexus in Bangladesh: Revisited evidences. Energy Policy, 39(10), 6145-6150.

Ha, N. M., \& Ngoc, B. H. (2020). Revisiting the relationship between energy consumption and economic growth nexus in Vietnam: new evidence by asymmetric ARDL cointegration. Applied Economics Letters. https://doi.org/10.1080/13504851. 2020.1789543

Ha, N. M., Ngoc, B. H., Duc, V. H., \& McAleer, M. (2019). Energy Consumption and Economic Growth: Evidence from Vietnam. Journal of Reviews on Global Economics, 8, 350-361. 
Hamdi, H., Sbia, R., \& Shahbaz, M. (2014). The nexus between electricity consumption and economic growth in Bahrain. Economic Modelling, 38, 227-237.

Hayrdaroglu, C. (2016). The Effect of Foreign Direct Investment and Economic Freedom on Economic Growth: The Case of BRICS Countries. Research in World Economy, 7(1).

Hussain, M., \& Haque, M. (2016). Foreign Direct Investment, Trade, and Economic Growth: An Empirical Analysis of Bangladesh. Economies, 4(4).

Hymer, S. H. (1976). The International Operations of National Firms: A Study of Direct Foreign Investment. Cambridge, MA: The MIT Press.

Ibrahiem, D. M. (2015). Renewable Electricity Consumption, Foreign Direct Investment and Economic Growth in Egypt: An ARDL Approach. Procedia Economics and Finance, 30, 313-323.

Irandoust, J. E. M. (2001). On the Causality between Foreign Direct Investment and Output: A Comparative Study. The International Trade Journal, 15(1), 1-26.

Jeffreys, H. (1962). Theory of Probability. Geophysical Journal International, 6(4), 555-558.

Kivyiro, P., \& Arminen, H. (2014). Carbon dioxide emissions, energy consumption, economic growth, and foreign direct investment: Causality analysis for Sub-Saharan Africa. Energy, 74, 595-606.

Kraft, J., \& Kraft, A. (1978). On the Relationship Between Energy and GNP. The Journal of Energy and Development, 3(2), 401-403.

Le, N. H., Duy, L. V. Q., \& Ngoc, B. H. (2019). Effects of Foreign Direct Investment and Human Capital on Labour Productivity: Evidence from Vietnam. Journal of Asian Finance, Economics and Business, 6(3), 123-130. https://doi.org/10.13106/ jafeb.2019.vol6.no3.123

Liu, Q., Wang, S., Zhang, W., Zhan, D., \& Li, J. (2018). Does foreign direct investment affect environmental pollution in China's cities? A spatial econometric perspective. Sci Total Environ, 613-614, 521-529.

Long, P. D., Ngoc, B. H., \& My, D. T. H. (2018). The relationship between foreign direct investment, electricity consumption and economic growth in Vietnam. International Journal of Energy Economics and Policy, 8(3), 267-274.

Markusen, J. R., \& Venables, A. J. (1999). Foreign direct investment as a catalyst for industrial development. European Economic Review, 43(2), 335-356.

Maryam, J., \& Mittal, A. (2020). Foreign direct investment into BRICS: an empirical analysis. Transnational Corporations Review, 12(1), 1-9.

Ngoc, B. H. (2019). Energy Consumption and Economic Growth Nexus in Vietnam: An ARDL Approach. In: Kreinovich V., Thach N., Trung N., Van Thanh D. (Eds.), Beyond Traditional Probabilistic Methods in Economics (Vol. 809, pp. 311-322), ECONVN 2019. Springer, Cham.
Ngoc, B. H. (2020). Effects of Foreign Direct Investment and Quality of Informal Institution on the Size of the Shadow Economy: Application to Vietnam. Journal of Asian Finance, Economics and Business, 7(5), 73-80. https://doi.org/10.13106/ jafeb.2020.vol7.no5.073

Ngoc, B. H., \& Hai, D. B. (2019). The Impact of Foreign Direct Investment on Structural Economic in Vietnam. In: Kreinovich V., Thach N., Trung N., Van Thanh D. (Eds.), Beyond Traditional Probabilistic Methods in Economics (Vol. 809, pp. 352-362), ECONVN 2019. Springer, Cham.

Nguyen, H. M., \& Ngoc, B. H. (2020). Energy Consumption Economic Growth Nexus in Vietnam: An ARDL Approach with a Structural Break. Journal of Asian Finance, Economics and Business, 7(1), 101-110. https://doi.org/10.13106/jafeb.2020. vol7.no1.101

Omri, A. (2014). An international literature survey on energyeconomic growth nexus: Evidence from country-specific studies. Renewable and Sustainable Energy Reviews, 38, 951959.

Osman, M., Gachino, G., \& Hoque, A. (2016). Electricity consumption and economic growth in the GCC countries: Panel data analysis. Energy Policy, 98, 318-327.

Payne, J. E. (2009). On the dynamics of energy consumption and output in the US. Applied Energy, 86(4), 575-577.

Pazienza, P. (2015). The relationship between CO2 and Foreign Direct Investment in the agriculture and fishing sector of OECD countries: Evidence and policy considerations. Intellectual Economics, 9(1), 55-66.

Pradhan, R. P., Arvin, M. B., \& Hall, J. H. (2019). The nexus between economic growth, stock market depth, trade openness, and foreign direct investment: The case of Asean countries. The Singapore Economic Review, 64(3), 461-493.

Prebisch, R. (1968). Global Strategy of Development and International Cooperation-Programme Before Unctad-II. Foreign Trade Review, 2(4), 359-371.

Rodrik, D., Subramanian, A., \& Trebbi, F. (2004). Institutions Rule: The Primacy of Institutions Over Geography and Integration in Economic Development. Journal of Economic Growth, 9(2), 131-165.

Sivalogathasan, V., \& Wu, X. (2014). The Effect of Foreign Direct Investment on Innovation in South Asian Emerging Markets. Global Business and Organizational Excellence, 33(3), 63-76.

Squalli, J. (2007). Electricity consumption and economic growth: Bounds and causality analyses of OPEC members. Energy Economics, 29(6), 1192-1205.

Tang, C. F. (2009). Electricity consumption, income, foreign direct investment, and population in Malaysia. Journal of Economic Studies, 36(4), 371-382. 
Temiz, D., \& Gökmen, A. (2014). FDI inflow as an international business operation by MNCs and economic growth: An empirical study on Turkey. International Business Review, 23(1), 145-154.

Thompson, S. K. (2012). Sampling (3rd ed.). Hoboken, NJ: John Wiley \& Sons. Inc.

Tiba, S., \& Omri, A. (2017). Literature survey on the relationships between energy, environment and economic growth. Renewable and Sustainable Energy Reviews, 69, 1129-1146.

Toda, H. Y., \& Yamamoto, T. (1995). Statistical inference in vector autoregressions with possibly integrated processes. Journal of Econometrics, 66(1-2), 225-250.

Zhang, C., Zhou, K., Yang, S., \& Shao, Z. (2017). On electricity consumption and economic growth in China. Renewable and Sustainable Energy Reviews, 76, 353-368. 